\title{
Adana ve Osmaniye illeri yerfıstığı üretim alanlarında Yeşilkurt, Helicoverpa armigera (Hübner) (Lepidoptera: Noctuidae)'nın yaygınlığı, bulaşıklık oranları ve popülasyon değişimi
}

\section{Distribution, infestation rates and population dynamics of Cotton Bollworm, Helicoverpa armigera (Hübner) (Lepidoptera: Noctuidae) in peanut production areas in Adana and Osmaniye provinces, Turkey}

\author{
Mahmut BADEMCi ${ }^{*}$ iD, Erdal SERTKAYA ${ }^{2}$ iD \\ ${ }^{1}$ Biyolojik Mücadele Araştırma Enstitüsü Müdürlüğü, Adana \\ ${ }^{2}$ Hatay Mustafa Kemal Üniversitesi, Ziraat Fakültesi, Bitki Koruma Bölümü, Hatay \\ ${ }^{1}$ https://orcid.org/0000-0002-6788-1987; ${ }^{2}$ https://orcid.org/0000-0001-9956-943X
}

\section{To cite this article:}

Bademci, M. \& Sertkaya, E. (2021). Adana ve Osmaniye illeri yerfıstığı üretim alanlarında Yeşilkurt, Helicoverpa armigera (Hübner)

(Lepidoptera: Noctuidae)'nın yaygınlığı, bulaşıklık oranları ve popülasyon değişimi. Harran Tarım ve Gıda Bilimleri Dergisi, 25(2):193-203. DOI: $10.29050 /$ harranziraat.891729

*Address for Correspondence: Mahmut BADEMCI e-mail:

mahmut.bademci@tarimorman.gov.tr

Received Date:

05.03.2021

Accepted Date:

24.05.2021

(c) Copyright 2018 by Harran University Faculty of Agriculture. Available on-line at www.dergipark.gov.tr/harranziraat

This work is licensed under a Creative Commons Attribution-Non
Commercial 4.0 International License.

\section{öz}

Adana ve Osmaniye illeri ülkemiz tarımında yerfıstığı üretim ve ekili alanın büyük bir bölümünü karşılayarak, ülke ekonomisine önemli katkı sağlamaktadır. Bu çalışma, Adana ve Osmaniye'de yerfıstığı ekim alanlarında zararlı Yeşilkurt [Helicoverpa armigera (Hübner) (Lep;Noctuidae)]'un yaygınlığı, bulaşıklığı ve popülasyon değişimini belirlemek amacıyla 2017 ve 2018 yıllarında yürütülmüştür. Zararlının larva ve ergin popülasyonu iki farklı tarlada haftalık olarak takip edilmiş olup, larva popülasyonu doğrudan bitki üzerinde sayım yapılarak, ergin popülasyonu ise funnel tipi feromon tuzak kullanılarak izlenmiştir. Yerfıstığı ekiminin yoğun olarak yapıldığı alanlarda, zararlının yaygınlığı ve bulaşıklığını belirlemek için haftalık sürveyler yapılmıştır. Tarla büyüklüğüne göre belirlenen beş farklı noktada sayımlar yapılarak, yaygınlık ve bulaşıklık durumu tespit edilmiştir. Zararlının larva popülasyonu 2017 yılında Osmaniye'de 14 larva/bitki ile Ekonomik Zarar Eşiğinin üzerine çıkmış ve insektisit uygulamasından sonra düşmüştür. Bunun dışında Adana ve Osmaniye'de zararlının popülasyonu Ekonomik Zarar Eşiğinin altında gerçekleşmiştir. Her iki ilde de 2017 yılında ergin popülasyonu temmuz ve eylül aylarında iki tepe noktasına ulaşmış, 2018 yılında ise düşük seviyede seyretmiştir. H. armigera ile bulaşıklık oranı 2017 ve 2018 yıllarında değişkenlik göstermiştir. Adana'da, 2017 yılında \%40.26 olan bulaşma oranı, 2018 yılında \%17.91 olarak gerçekleşmiştir. Osmaniye'de ise 2017 ve 2018 yıllarında bulaşıklık oranı sırası ile \%36.36 ve \%48.28 olmuştur. 2017 yılında tarla içi bulaşıklık her iki ilde de 0.2-1.0 larva/bitki iken, 2018 yılında 0.2-0.8 larva/bitki olarak gerçekleşmiştir. Sürvey yapılan üretim alanlarında H.armigera'nın birinci ürün olarak yetiştirilen yerfıstığında ekonomik anlamda sorun teşkil etmediği ancak ikinci ürünün çiçeklenme döneminde dikkat edilmesi ve bu konuda araştırma yapılması önerilmektedir.

Anahtar Kelimeler: Adana, Osmaniye, Yeşilkurt, Yerfıstığı, Popülasyon değişimi

\section{ABSTRACT}

Adana and Osmaniye are the provinces with the highest share in the field of peanut production and cultivation in the country and make a great contribution to the country's economy. This study was carried out in Adana and Osmaniye provinces of Turkey in 2017 and 2018 to determine the distribution, infestation and population dynamic of cotton bollworm [Helicoverpa armigera (Hübner) (Lepidoptera; Noctuidae)] in peanut cultivation areas. The larval and adult populations of the pest were followed weekly in two different fields, the larval population was directly counted on the plant, and the adult population was monitored using a funnel type pheromone trap. Field controls in areas where peanuts 
planted intensively were conducted weekly to determine the distribution and infestation of the pest. The distribution and infestation status were determined at five different points according to the field size. The larvae population of the pest rise above the Economic Damage Threshold (EDT) with 14 larvae / plants in Osmaniye and decreased after insecticide application, in 2017. Other than in 2018, the population of the pests in Adana and Osmaniye was below the (EDT). The adult population in Adana and Osmaniye reached two peaks in July and September in 2017 and remained low in 2018. The infestation rate of $H$. armigera in peanuts varied in 2017 and 2018 . While the infestation rate in Adana was $40.26 \%$ and $17.91 \%$ in 2017 and 2018 respectively. In Osmaniye, the infestation rate was 36.36\% in 2017 and $48.28 \%$ in 2018. In 2017, while the infestation in the field was 0.2-1.0 larvae / plant in Adana and Osmaniye, it was 0.2-0.8 larvae / plant in 2018. In the surveyed peanut fields, $H$. armigera does not cause economic damage on the first peanut crop, but on the second peanut crop it can cause economic damage during the flowering period. It was concluded that detailed research is recommended on this subject.

Key Words: Adana, Osmaniye, Cotton bollworm, peanut, population dynamic

\section{Giriş}

Güney Amerika kökenli, baklagiller familyasından tek yıllık yazlık ve yağlı tohumlu bir kültür bitkisi olan yerfıstığı (Arachis hypogaea L.) insan beslenmesinde, hayvan yemi olarak kullanımının yanısıra toprağa azot bağlaması bakımından önemli bir yağ bitkisidir (Arıŏlu, 2014). İçerdiği yağ, protein, karbonhidrat, vitaminler ve mineral maddeler nedeniyle insanlar ve hayvanlar için değerli bir besin kaynağıdır (Arıoğlu ve Arıoğlu, 2007). Yerfıstığının tarımı 40 kuzey ve $30^{\circ}$ güney enlemleri arasında, tropik bölgelerden orta enlemlere kadar bir alanda yapılır (Öğütçü, 1969). Dünyada üretilen 44043 895 ton yerfıstığının 16860000 ton ile \% 38'ni üreten Çin 1. sırada yer alırken, Türkiye 164186 ton ile \% 0.37'sini üreterek 28. sırada yer almaktadır (Anonymous, 2016).

Yerfıstığı Çukurova bölgesinde ana ürün ve buğday hasadından sonra ikinci ürün olarak yetiştirilmekte, verim potansiyeli, pazarlama kolaylığı ve birim alandan elde edilen gelirin yüksek olması nedenleri ile Çukurova bölgesindeki çiftçiler için oldukça avantajı bitkilerden birisidir. Türkiye'de yerfıstığı üretiminin \% 80'i Osmaniye, Adana ve İçel illerinde gerçekleşmektedir (Arıoğlu, 2007). Türkiye'de 2018 yılında 443342 dekarda 173835 ton yerfıstığı üretilmiştir. Bu üretim daha çok Akdeniz Bölgesinde, özellikle Adana ve Osmaniye illerinden elde edilmektedir. Bu iki il, 369859 dekar ile Türkiye yerfıstığı üretim alanlarının \% 83'ünü, 146466 ton ile üretim miktarının \% 84'ünü karşılamaktadır (Anonim, 2018).

Birim alandan daha fazla ürün almak tarımda önemli konulardan biridir. Tarımsal üretimde üründe kalite ve verim kayıplarının başlıca nedeni karşılaşılan çok sayıda hastalık ve zararlı Arthropod türlerdir. Türkiye'de yerfıstığı yetiştiriciliğini olumsuz yönde etkileyen zararlılardan bazıları Kırmızıörümcek (Tetranychus urticae Boisd) (Acarina: Tetranychidae), Duponchelia fovealis Zeller (Lepidoptera: Pyralidae), Pamuk çizgili yaprakkurdu (Spodoptera exigua Hbn.) (Lepidoptera: Noctuidae), Pamuk yaprakkurdu (Spodoptera littoralis Boisd.) ve Yeşilkurt (Helicoverpa armigera Hübner) (Lepidoptera: Noctuidae)'tur (Anonim, 2012).

Dünyanın pek çok yerinde bulunan ve konukçu dizisi geniş olan $H$. armigera, ülkemizde ilk defa 1913 yılında Bergama'da tespit edilmiştir (Alkan, 1948). Zararlı Çukurova Bölgesi'nde 1954 yılında pamuk alanlarında görülmüş ve 1974 yılında "Pamuk Zararlıları ile Entegre Savaşım" projesi kapsamına alınmıştır (Yabaş, 1979). Erginler günün karanlık periyodunda faaliyet gösterirken, gündüzleri aktiviteleri çok azdır ve kuytu yerlerde gizlenmektedirler. Pupadan ergin çıkışı ve yumurtlamanın da genel olarak günün karanlık saatlerinde gerçekleştiği bildirilmiştir (Yabaş, 1979). H. armigera'nın yılda verdiği döl sayısı bölgelere göre değişiklik göstermekte olup Adana'da 5, Bursa'da 4, Manisa'da ise 4-5 döl verdiği bildirilmektedir (Yabaş, 1979; Kaya ve Kovancı, 2000; Koçlu ve Karsavuran, 2000).

Son yıllarda Çukurova'da pamuk ekiminin oldukça azalmış olması nedeni ile zararlının aynı dönemde yetiştirilen diğer konukçu bitkilere yöneldiği gözlenmiştir. Bu bitkilerden bir tanesi de yerfıstığı olup, son yıllarda üreticilerden bu konuda şikayetler gelmektedir. 
Helicoverpa armigera'nın larva dönemi yerfıstığının, yaprak ve çiçek kısımları ile iğnede (ginofor) zarar vermektedir. Zarar gören iğneler toprağa girip tohum oluşturamadığından yerfıstığında verim yönünden kayıplara neden olmaktadır (Anonim, 2012). Dünyada bu konuyla ilgili çeşitli araştırmalar yapılmış olmasına rağmen ülkemizde yapılmış bir çalışmaya rastlanılmamıştır. Çalışma bu nedenle ele alınmış olup, zararlının ülkemizin en önemli yerfıstığı üretim alanlarını barındıran Adana ve Osmaniyeillerindeki yaygınlık ve bulaşıklık oranlarının ve, popülasyon değişiminin belirlenmesi amaçlanmıştır.

\section{Materyal ve Yöntem}

\section{Materyal}

Çalışmanın ana materyalini, Adana ve Osmaniye illerinde bulunan yerfıstığı üretim alanları, H. armigera'nın ergin ve larvaları, funnel tipi tuzak, feromon, dichlorvos emdirilmiş tablet ve plastik beyaz küvetler oluşturmuştur.

\section{Yöntem}

Adana ve Osmaniye illeri yerfıstığı üretim alanlarında Helicoverpa armigera' nın yaygınlığı ile bulaşıklık oranlarının belirlenmesi

Adana ve Osmaniye illeri yerfıstığı alanlarında H. armigera' nın yaygınlığı ile bulaşıklık oranlarını saptamak amacı ile yerfıstığı tarımının yoğun olarak yapıldığı alanlarda örneklemeler yapılmıştır.

Örneklemeler 2017 ve 2018 yıllarında MayısEylül aylarında haftada bir yapılmıştır. Arazi çalışmalarında her ili temsil edecek şekilde yerfıstığı alanlarının, \% 0.01'i esas alınarak, yerfıstığı alanlarında örnekleme yapılmıştır (Bora ve Karaca, 1970).

Yaygınlık ve bulaşıklığının belirlenmesinde 1-50 dekarlık alan 1 ünite kabul edilmiştir. Örnekleme yapılan alanın büyüklüğüne göre belirlenen her ünitede en az 5 farklı noktada yan yana iki adet bitki kontrol edilmiştir. (Anonim, 2012). Örneklemelerde $H$. armigera'nın herhangi bir biyolojik dönemi ya da zarar şekli görüldüğü takdirde o alan bulaşık olarak kabul edilmiştir. Bulaşık bulunan tarlalarda zararlının tarla içi bulaşıklığını belirlemek için örnekleme yapılan tarlada bulunan toplam larva sayısı, örnekleme yapılan bitki sayısına bölünerek bitki başına larva sayısı belirlenmiştir.

Yerfıstığında Helicoverpa armigera' nın ergin ve ergin öncesi dönemlerinin popülasyon değişimi

Yerfıstığında Yeşilkurt'un larva ve ergin dönemlerinin popülasyon takibi 2017 ve 2018 yıllarında Adana ve Osmaniye illerinde Mayıs ve Eylül ayları arasında birinci üründe birer adet tarlada yapılmıştır. Popülasyon takibi için haftada bir kez arazi çıkışı yapılmıştır (Çizelge 1).

Çizelge 1. Helicoverpa armigera'nın popülasyon takibi yapılan alan ile ilgili bilgiler

Table 1. Information on the area where the population of Helicoverpa armigera is monitored

\begin{tabular}{|c|c|c|c|c|}
\hline $\begin{array}{c}\text { ill } \\
\text { Province }\end{array}$ & Year & $\begin{array}{l}\text { Yerfıstığının } \\
\text { Çeşidi } \\
\text { Type of } \\
\text { Peanut }\end{array}$ & $\begin{array}{l}\text { Tuzakların } \\
\text { Asıldığı } \\
\text { Tarih } \\
\text { The Date } \\
\text { the Traps } \\
\text { were } \\
\text { Hanged }\end{array}$ & $\begin{array}{l}\text { Tuzakların } \\
\text { Kaldırıldığı } \\
\quad \text { Tarih } \\
\text { Date Traps } \\
\quad \text { Lifted }\end{array}$ \\
\hline \multirow[t]{2}{*}{ Adana } & 2017 & NC-7 & 02.06 .2017 & 22.09 .2017 \\
\hline & 2018 & Sultan & 29.05.2018 & 06.09 .2018 \\
\hline \multirow[t]{2}{*}{ Osmaniye } & 2017 & NC-7 & 29.05.2017 & 25.09 .2017 \\
\hline & 2018 & NC-7 & 29.05 .2018 & 03.09.2018 \\
\hline
\end{tabular}

Zararlının ergin popülasyon takibi için 1 tuzak/da olacak şekilde funnel tipi tuzak, feromon ve Dichlorvos (DDVP) emdirilmiş tablet kullanılmıştır. Tuzaklardaki erginler haftalık olarak sayılıp kaydedilmiştir. Tuzaklardaki feromonlar 4 haftada bir yenileri ile değiştirilmiştir.

Zararlının larva popülasyon değişimini tespit için tarlanın en az 5 farklı noktasında yan yana iki bitki kontrol edilmiştir (Anonim, 2012). Her örnekleme tarihinde bitki başına larva sayıları kaydedilmiş ve daha sonra bu verilere dayanarak popülasyon eğrileri oluşturulmuştur.

\section{Bulgular ve Tartışma}

Adana ve Osmaniye yerfıstığı alanlarında Helicoverpa armigera'nın yaygınlığı ve bulaşıklığının belirlenmesi

Adana ilinde $H$. armigera'nın yaygınlığı ile 
bulaşıklığının belirlenmesi amacıyla 2017 yılında Yüreğir, Karataş, Kozan, Ceyhan ve Yumurtalık ilçelerinde 43 köyde toplam 77 tarlada örnekleme yapılmış ve 31 tarla zararlı ile bulaşık bulunmuştur. Örnekleme yapılan toplam $5297 \mathrm{da}$ alanda zararlının bulaşma oranı \% 40.26 olarak tespit edilmiştir. Çalışma yapılan ilçelerden yalnızca Kozan'da bulaşıklık tespit edilmemiştir (Çizelge 2). Yapılan çalışmada tarla içi bulaşıklık en fazla Ceyhan ilçesinin Ceyhanbekirli ve Karakayalı köyleri ile Yumurtalık ilçesinin Yeniköy ve Ayvalık köylerinde tespit edilmiştir. Adana ilinde 2018 yılında ise Yüreğir, Sarıçam, Karataş, Kozan, Ceyhan ve Yumurtalık ilçelerinde 33 köyde toplam 67 tarlada örnekleme yapılmış, 12 tarla zararlı ile bulaşık bulunmuştur. Örnekleme yapılan toplam alanın büyüklüğü 4567 da, zararlının bulaşma oranı \% 17.91 olarak bulunmuştur (Çizelge 2). Yapılan çalışmada 2017 yılında bulaşıklık bulunmayan Kozan ilçesinde, 2018 yılında en yüksek bulaşıklık oranı saptanmıştır. Tarla içi bulaşıkık en fazla Kozan merkezde tespit edilmiştir.

Çizelge 2. Adana'da 2017-2018 Yılında yerfıstığında Helicoverpa armigera'nın yaygınlığı ve bulaşma oranları

Table 2. Prevalence and infestation rate of of Helicoverpa armigera in peanut in Adana in 2017-2018

\begin{tabular}{|c|c|c|c|c|c|c|c|}
\hline Yer & & $\begin{array}{l}\text { Tarla sayısı } \\
\text { 2017-2018 }\end{array}$ & $\begin{array}{c}\text { Bulaşık tarla } \\
\text { sayısı }\end{array}$ & $\begin{array}{l}\text { Sürvey yapılan } \\
\text { alan (da) }\end{array}$ & $\begin{array}{c}\text { Bulaşma oranı } \\
(\%)\end{array}$ & $\begin{array}{l}\text { Bulaşıklık } \\
\text { (larva/bitki) }\end{array}$ & $\begin{array}{l}\text { Sürvey tarihi } \\
2017-2018\end{array}$ \\
\hline il & İlçeler & Number & 2017-2018 & 2017-2018 & 2017-2018 & Infestation & Surveyed time \\
\hline Province & Districts & 2017-2018 & $\begin{array}{l}\text { Number of } \\
\text { infested field } \\
2017-2018\end{array}$ & $\begin{array}{c}\text { surveyed (da) } \\
2017-2018\end{array}$ & $\begin{array}{c}\text { (\%) } \\
2017-2018\end{array}$ & 2017-2018 & \\
\hline \multirow{7}{*}{$\frac{\frac{\pi}{5}}{\frac{0}{0}}$} & Yüreğir & $12-3$ & $4-1$ & $1039-153$ & 33.33-33.33 & $0-0.8 / 0-0.2$ & 11 Ağu-16 Ă̆u \\
\hline & Sarıçam & $0-2$ & $0-0$ & $0-30$ & $0-0$ & $0-0$ & \\
\hline & Karataş & $12-15$ & $6-1$ & 736-1094 & $50-6.67$ & $0-0.6 / 0-0.6$ & 7Tem-30 Tem \\
\hline & Kozan & $4-11$ & $0-7$ & $248-502$ & $0-63.63$ & $0 / 0.6-0.8$ & -17 Tem \\
\hline & Ceyhan & $34-19$ & $16-2$ & $1964-1783$ & $47.05-10.53$ & $0-1.0 / 0-0.4$ & 17Tem-30Tem \\
\hline & Yumurtalık & $12-17$ & $5-1$ & 1310-1005 & $41.67-5.88$ & $0-1.0 / 0-0.2$ & 7Tem-24Tem \\
\hline & TOPLAM & $77-67$ & $31-12$ & $5297-4567$ & $40.26-17.91$ & $0-1.0 / 0-0.8$ & \\
\hline
\end{tabular}

Osmaniye ilinde $H$. armigera'nın yaygınlık ve bulaşıklığının belirlenmesi amacıyla 2017 yılında Merkez, Kadirli, Düziçi ve Sumbas ilçelerinde 36 köyde toplam 66 tarlada örnekleme yapılmış, 24 tarla zararlı ile bulaşık bulunmuştur. Örnekleme yapılan toplam alanın büyüklüğü 1626 da, zararlının bulaşma oranı ise \% 36.36 olarak tespit edilmiştir (Çizelge 3). Tarla içi bulaşıklık en fazla Kadirli ilçesinin Aydınlar köyünde tespit edilmiştir.
Osmaniye ilinde 2018 yılında ise Merkez, Düziçi, Kadirli ve Sumbas ilçelerinde 20 köyde toplam 29 tarlada örnekleme yapılmış, 14 tarla zararlı ile bulaşık bulunmuştur. Örnekleme yapılan toplam alanın büyüklüğü 963 da, zararlının bulaşma oranı \% 48.28 olarak tespit edilmiştir (Çizelge 3). Tarla içi bulaşıklık en fazla Düziçi ilçesi Ellek beldesinde tespit edilmiştir.

Çizelge 3. Osmaniye' de 2017-2018 yılında yerfıstığında Helicoverpa armigera'nın yaygınlı̆̆ı ve bulaşma miktarı Table 3. Prevalence and contamination amount of Helicoverpa armigera in peanut in Osmaniye in 2017-2018

\begin{tabular}{|c|c|c|c|c|c|c|c|}
\hline Yer & & $\begin{array}{l}\text { Tarla sayısı } \\
2017-2018\end{array}$ & $\begin{array}{c}\text { Bulaşık tarla } \\
\text { sayısı }\end{array}$ & $\begin{array}{l}\text { Sürvey yapılan } \\
\text { alan (da) }\end{array}$ & $\begin{array}{c}\text { Bulaşma oranı (\%) } \\
\text { 2017-2018 }\end{array}$ & $\begin{array}{c}\text { Bulaşıklık } \\
\text { (larva/bitki) }\end{array}$ & $\begin{array}{l}\text { Sürvey tarihi } \\
\text { 2017-2018 }\end{array}$ \\
\hline $\begin{array}{l}\text { Ill } \\
\text { Location } \\
\text { Province }\end{array}$ & $\begin{array}{l}\text { İlçeler } \\
\text { Districts }\end{array}$ & $\begin{array}{l}\text { Number } \\
\text { of fields } \\
2017-2018\end{array}$ & $\begin{array}{l}\text { 2017-2018 } \\
\text { Number of } \\
\text { infested field } \\
2017-2018\end{array}$ & $\begin{array}{l}2017-2018 \\
\text { The fields of } \\
\text { surveyed (da) } \\
2017-2018\end{array}$ & $\begin{array}{c}\text { Infestation rate } \\
\text { (\%) } \\
2017-2018\end{array}$ & $\begin{array}{l}\text { Infestation } \\
\text { (larvae/plant) } \\
2017-2018\end{array}$ & $\begin{array}{c}\text { Surveyed time } \\
2017-2018\end{array}$ \\
\hline \multirow{5}{*}{  } & Merkez & $15-5$ & $4-3$ & $399-182$ & $26.67-60$ & $0-0.8 / 0-0.4$ & 24 Tem-6 Ağu \\
\hline & Düziçii & $19-13$ & $5-7$ & $101-140$ & $26.32-53.85$ & $0-0.8 / 0-0.8$ & 10 Tem-10Tem \\
\hline & Kadirli & $14-13$ & $3-3$ & $881-571$ & $21.43-23.07$ & $0-1.0 / 0-0.4$ & 3 Tem-30 Tem \\
\hline & Sumbas & $9-1$ & $5-1$ & $245-70$ & $55.56-100$ & $0-0.6 / 0.6$ & 3 Tem-16Tem \\
\hline & TOPLAM & $66-29$ & $24-14$ & $1626-963$ & $36.36-48.28$ & $0-1.0 / 0-0.8$ & \\
\hline
\end{tabular}

Helicoverpa armigera yaygınlık çalışmasında 2017 yılında örnekleme yapılan alanlarda Adana ilinde 77 tarlanın $31^{\prime} \mathrm{i}$ bulaşık bulunurken, Osmaniye'de ise 66 tarlanın 24'ü zararlı ile bulaşık 
bulunmuştur. Çalışmanın 2. yılında Adana'da 58 tarlanın 7'si, Osmaniye'de ise 29 tarlanın 14'ü zararlı ile bulaşık bulunmuştur. Zararlının bulaşma oranı Adana'da 2017 yılında \% 40.26 iken 2018 yılında ise \%17.91 olarak bulunmuştur. Zararlının bulaşma oranı 2018 yılında 2017 yılına göre önemli ölçüde azalış göstermiştir. Adana'da örnekleme yapılan tarlalarda $H$. armigera'nın 2017 yılında tarla içi bulaşıklığı 0.2-1.0 larva/bitki arasında değişkenlik gösterirken 2018 yılında ise 0.2-0.8 larva/bitki arasında değişkenlik göstermiştir. Örnekleme yapılan tarlalarda $H$. armigera'nın tarla içi bulaşıklığı bulaşma oranına benzer bir şekilde 2018 yılında 2017 yılına göre düşüş göstermiştir (Çizelge 2). Bu durumun pupadan bahar aylarındaki ergin çıkışlarını ve popülasyonu olumsuz etkilediği düşünülmektedir. Diyarbakır ilinde domateste $H$. armigera'nın popülasyon gelişimi, parazitoit ve predatörlerinin belirlenmesi çalışmasında kış aylarında görülen eksi sıcaklık değerlerinin Yeşilkurt'un bahar aylarındaki ergin popülasyonunu olumsuz etkilediği bildirilmiştir (Karapınar ve Sertkaya 2020). Yeşilkurt kışı pupa olarak 2.5-8 cm derinlikte toprakta geçirmektedir (Öngören ve ark 1977.; Kaya ve Kovancı 2000). Yeşilkurt'un ilk ergin uçuşları Çukurova'da Nisan başından itibaren görülmektedir (Uygun ve ark., 2009). Adana'da çalışma yapılan yıllarda alınan iklimsel verilere bakıldığında kış mevsimi boyunca yağışı gün sayısı ve yağış miktarının 2017 yılına göre çok fazla olduğu görülmektedir (Şekil 1).

Zararlı ile bulaşma oranı Osmaniye'de 2017 yılında \% 36.26 iken 2018 yılında ise \% 48.28 bulunmuştur. H. armigera'nın Osmaniye'de 2017 yılında tarla içi bulaşıklığı 0.2-1.0 larva/bitki iken, 2018 yılında 0.2-0.8 larva/bitki olarak belirlenmiştir. Hindistan'da yerfıstığında $H$. armigera'nın popülasyon dinamiği ve yönetimi çalışmasında bitki başına larva sayısı 1.43 ile 2.06 arasında değiştiği ve yerfıstığı yapraklarında ise \%35 oranında zarar yaptığı tespit edilmiştir (Naik ve ark. 2013). Hindistan'da yapılan bir çalışmada yerfıstığı deneme alanında Spodoptera litura' nın $\% 30, H$. armigera 'nın \% 28 oranında yapraklarda zarara yol açtığı bildirilmiştir (Sharmıla ve Manjula 2015).
Ülkemizde yapılan çalışmalarda $H$. armigera'nın yerfıstığında Ekonomik Zarar Eşiği (EZE) 5 larva/bitki olarak belirtilmiştir (Anonim, 2012). Adana ve Osmaniye'de örnekleme yapılan alanlarda hem 2017 hem de 2018 yılında zararlının EZE'nin üstüne çıkmadığı belirlenmiştir. Bu çalışmanın yürütüldüğü 2017 ve 2018 yıllarında ana ürün olarak yerfıstığı Adana ve Osmaniye'de büyük ölçüde Nisan ayının 2 . haftasına kadar ekilmiş, haziran ayı başında başlayan çiçeklenme ve ginofor oluşumu ay sonuna kadar devam etmiştir. Yerfıstığı alanlarında $H$. armigera örneklemelerinin yapıldığı zaman aralığında zararlının ilk tespiti Adana'da 07.07.2017 ile 17.07.2018, Osmaniye'de ise 03.07.2017 ile 10.07.2018'de yapılmıştır. Yerfıstığında $H$. armigera larvalarının tespit edilmesi ana üründe çiçeklenme dönemi tamamlandıktan sonraki döneme rastlamaktadır. $\mathrm{Bu}$ yüzden $H$. armigera larvalarının çiçeklenme döneminde çiçekte ve ginoforlarda zararı tespit edilmemekle birlikte yerfıstığında yaprakta zarar meydana getirdiği tespit edilmiştir.

Zararlının örneklemesinin yapıldığı alanlarda $S$. exigua ve $S$. littoralis (Boisd.) larvaları tespit edilmiş ve bu alanlarda yapraklarda zarar meydana getirmiştir. S. exigua ve $S$. littoralis'in ZMTT'de EZE 5 larva/bitki olarak belirtilmiştir (Anonim, 2012). Her iki zararlının da tarla içi bulaşma oranı 1-2 larva/bitki ile EZE değerinin altında bulunmuştur. Buna karşın üreticilerin birçok alanda bu zararlıların yapraklarda neden olduğu zarardan dolayı insektisit uygulaması yaptıkları ve genel olarak bu zararlıları $H$. armigera' dan ayırt edemedikleri gözlenmiştir.

Yerfıstığında Helicoverpa armigera'nın ergin ve ergin öncesi dönemlerinin popülasyon değişimi

Zararlının popülasyon takibi için ergin sayımına 09.06.2017'de başlanmış ve 22.09.2017'ye kadar devam edilmiştir. Illk ergin tuzağa 09.06.2017'de yakalanmış, zararlının ergin popülasyonu ise 14.07.2017 ilk tepe noktasında 18 ergin sayılmış, 08.09.2017'de 27 ergin ile ikinci tepe noktasına ulaşmıştır (Şekil 1). Zararının illk larva tespiti 07.07.2017'de yapılmış, larva popülasyonu ise 
21.07.2017'de 1.6 larva/bitki ile en yüksek noktasına ulaşmıştır. Popülasyon takibinin yapıldığı dönemde meteorolojik verilere bakıldığında maksimum sıcaklık 30 Haziran'da $36.1{ }^{\circ} \mathrm{C}$ ve 15 Eylül'de $36.5^{\circ} \mathrm{C}$, minimum sıcaklık ise 23 Haziran'da $17.3{ }^{\circ} \mathrm{C}$, 8 Eylül'de $16.3{ }^{\circ} \mathrm{C}$ ölçülmüştür. Bağıl nem ise popülasyon takibinin yapıldığı dönemin başından sonuna kadar \%70'in üzerinde seyretmiştir (Şekil 1).
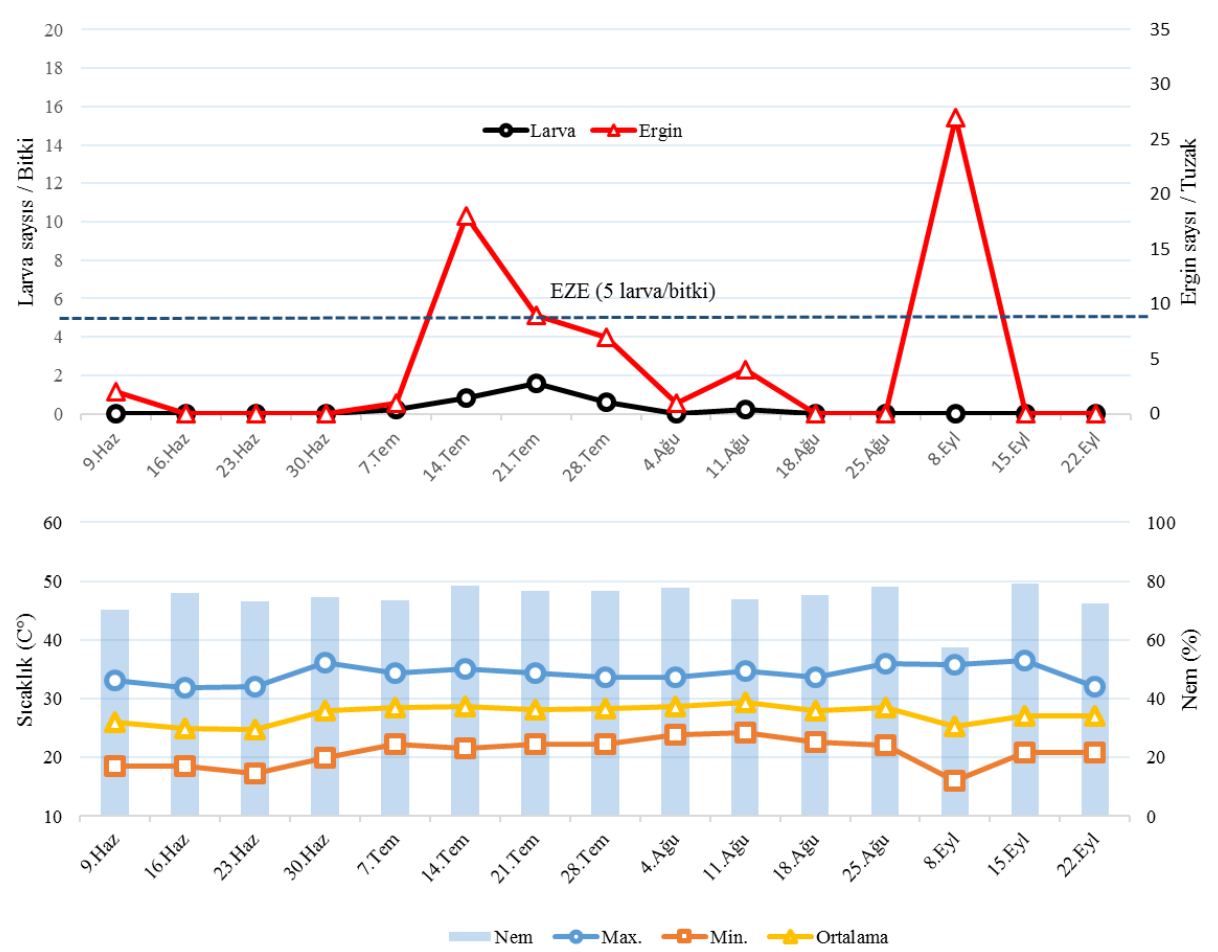

Şekil 1. Adana'da 2017 yılında yerfıstığında Helicoverpa armigera 'nın ergin ve larva popülasyonu ile meteorolojik veriler

Figure 1. Meteorological data with the adult and larval population of Helicoverpa armigera in peanuts in Adana in 2017

Helicoverpa armigera'nın popülasyon takibine başlanmadan önceki iklim verileri incelendiğinde Kasım 2016 - Mayıs 2017 aylarında toplamda 51 günün yağışlı olduğu görülmektedir. $\mathrm{Bu}$ süre içerisinde toplamda $304.1 \mathrm{~mm}$ yağış düştüğü, en fazla yağış Mart ayında 12 günde $95.4 \mathrm{~mm}$ olarak kayıt edilmiştir (Çizelge 4).

2017 yılında Osmaniye'de ilk ergin sayımına 05.06.2017'de başlanmış ve 25.09.2017'ye kadar devam edilmiştir. Tuzakta ilk ergin 12.06.2017'de yakalanmış, tepe noktasına ise 17.07 .2017 'de 10 ergin ile ilk tepe noktasında ulaşılmış, 11.09.2017 tarihinde de 32 ergin ile ikinci tepe noktası meydana gelmiştir. Zararlının larva popülasyonunun değişimini tespit etmek için larva sayımına 05.06.2017'de başlanmış ilk larva tespiti 28.06.2017'de yapılmıştır. Larva popülasyonu 17.07.2017'de 14 larva/bitki ile tepe noktasına ulaşmış ve EZE'nin üzerine çıkmıştır. Bu tarihte maksimum, minimum ve ortalama sıcaklık sırasıyla $37.6^{\circ} \mathrm{C}, 23^{\circ} \mathrm{C}$ ve $29.9^{\circ} \mathrm{C}$, bağıl nem ise $\% 67.8$ olarak ölçülmüştür (Şekil 2.). Çalışma alanında zararıının EZE'nin üstüne çıkmasından dolayı Araştırma Enstitüsünce bu alanda 18.07 .2017 'de insektisit uygulaması yapılmıştır ve popülasyon düşük seviyede kaldığından ikinci defa insektisit uygulamasına ihtiyaç duyulmamıştır. Popülasyon takibinin yapıldığı dönemde meteorolojik verilere bakıldığında 3 Temmuz'da maksimum sıcaklık 38.2 ${ }^{\circ} \mathrm{C}$ olarak minimum sıcaklık ise 5 Haziran'da $18{ }^{\circ} \mathrm{C}$ olarak ölçülmüştür. Bağıl nem ise popülasyon takibinin yapıldığı dönemin genelde \% 60'ın üzerinde seyretmiş, en yüksek bağıl nem değeri 14 Ağustosta \% 73.6 olarak ölçülmüştür (Şekil 2.). 
Çizelge 4. Adana'da 2017 yılında H. armigera'nın popülasyon takibi yapılmadan önceki dönemde toplam yağış ve yağışlı gün sayısı Table 4. Total number of rainy and rainy days in Adana in 2017 before the population monitoring of $\mathrm{H}$. armigera

\begin{tabular}{|c|c|c|}
\hline $\begin{array}{l}\text { Aylar } \\
\text { Months }\end{array}$ & $\begin{array}{c}\text { Yağış miktarı ( } \mathrm{mm} \text { ) } \\
\text { Rainfall }\end{array}$ & $\begin{array}{l}\text { Yağışlı gün sayısı } \\
\text { Rainy days number }\end{array}$ \\
\hline Kasım & 7.1 & 4 \\
\hline \multicolumn{3}{|c|}{ November } \\
\hline Aralık & 8 & 2 \\
\hline \multicolumn{3}{|c|}{ December } \\
\hline Ocak & 64.6 & 11 \\
\hline \multicolumn{3}{|l|}{ January } \\
\hline Şubat & 3 & 1 \\
\hline \multicolumn{3}{|l|}{ February } \\
\hline Mart & 95.4 & 12 \\
\hline \multicolumn{3}{|l|}{ March } \\
\hline Nisan & 55.5 & 11 \\
\hline \multicolumn{3}{|l|}{ April } \\
\hline Mayıs & 70.5 & 10 \\
\hline \multicolumn{3}{|l|}{ May } \\
\hline Toplam & 304.1 & 51 \\
\hline Total & & \\
\hline
\end{tabular}

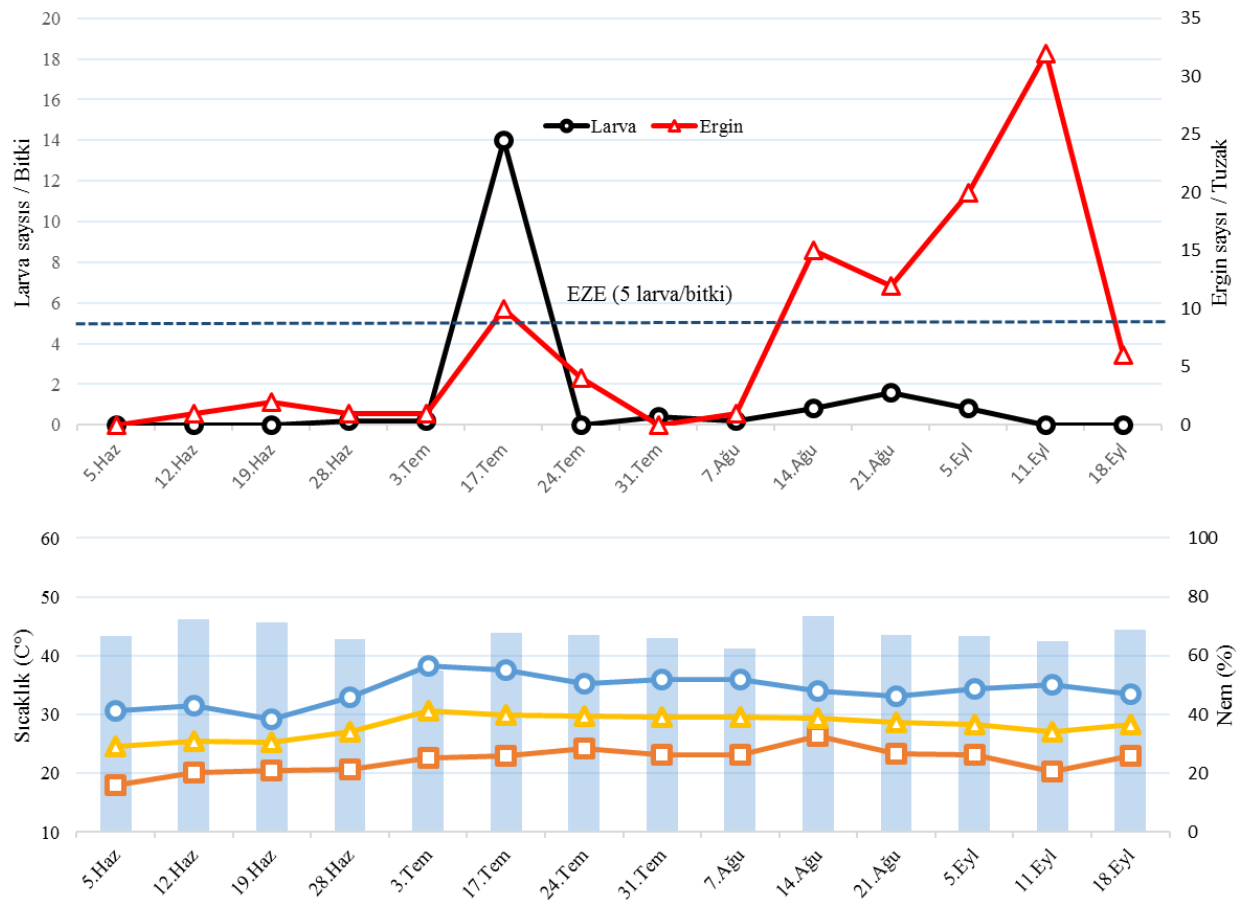

- Nem $-0-$ Max. $-a-$ Min. $\rightarrow-$ Ottalama

Şekil 2. Osmaniye'de 2017 yılında yerfıstığında Helicoverpa armigera 'nın ergin ve larva popülasyonu ile meteorolojik veriler Figure 2. Meteorological data with the adult and larval population of Helicoverpa armigera in peanuts in Osmaniye in 2017

H. armigera'nın popülasyon takibine başlanmadan önceki iklim koşullarına bakıldığında Kasım 2016 - Mayıs 2017 aylarında toplamda 64 günün yağışlı olduğu görülmektedir. Bu süre içerisinde toplamda $663.5 \mathrm{~mm}$ yağış düştüğü, en fazla yağış Mayıs ayında 9 günde 188.8 mm olarak kayıt edilmiştir (Çizelge 5).

Zararlının popülasyon takibi için ergin sayımına Adana'da 05.06.2018'de başlanmış ve 06.09.2018'e kadar devam edilmiştir. Tuzakta ilk ergin 05.06.2018' de yakalanmış, 16.08.2018'de ilk tepe noktasında 8 ergin sayılmış, 06.09.2018'de 7 ergin ile ikinci tepe noktasına ulaşmıştır. Zararlının larva popülasyonunun değişimini tespit etmek için larva sayımına 05.06 .2018 'de başlanmış ve sayımlarda $H$. armigera larvası tespit edilememiştir. Araştırma Enstitüsünce denemenin yürütüldüğü alanda Temmuz ayının ilk haftasında yapıldığı belirtilen ilaçlamanın buna neden olduğu düşünülmektedir. Popülasyon takibinin yapıldığı dönemde meteorolojik verilere bakıldığında maksimum sıcaklık 9 Ağustos'ta $35.8^{\circ} \mathrm{C}$, minimum 
sıcaklık ise 2 Temmuz' da $19{ }^{\circ} \mathrm{C}$ olarak ölçülmüştür. Bağıl nem ise popülasyon takbinin yapıldığı dönemin genelde \% 70'in üzerinde seyretmiş, en yüksek bağıl nem değeri 24 Temmuz'da \%86.2 olarak ölçülmüştür (Şekil 3.).

Çizelge 5. Osmaniye'de 2017 yılında H. armigera'nın popülasyon takibi yapılmadan önceki dönemde toplam yağış ve yağışlı gün sayısı

Table 5. Total number of rainy and rainy days in Osmaniye in 2017 before the population monitoring of H. armigera

\begin{tabular}{|c|c|c|}
\hline $\begin{array}{c}\text { Aylar } \\
\text { Months }\end{array}$ & $\begin{array}{c}\text { Yağış miktarı }(\mathrm{mm}) \\
\text { Rainfall }\end{array}$ & $\begin{array}{l}\text { Yağışlı gün sayısı } \\
\text { Rainy days number }\end{array}$ \\
\hline $\begin{array}{c}\text { Kasım } \\
\text { Novembe }\end{array}$ & 29.8 & 3 \\
\hline $\begin{array}{c}\text { Aralık } \\
\text { Decembe }\end{array}$ & 80 & 16 \\
\hline $\begin{array}{c}\text { Ocak } \\
\text { January }\end{array}$ & 142.2 & 11 \\
\hline $\begin{array}{l}\text { Şubat } \\
\text { February }\end{array}$ & 0.5 & 2 \\
\hline $\begin{array}{c}\text { Mart } \\
\text { March }\end{array}$ & 84.9 & 13 \\
\hline $\begin{array}{l}\text { Nisan } \\
\text { April }\end{array}$ & 137.3 & 10 \\
\hline $\begin{array}{l}\text { Mayıs } \\
\text { May }\end{array}$ & 188.8 & 9 \\
\hline $\begin{array}{c}\text { Toplam } \\
\text { Total }\end{array}$ & 663.5 & 64 \\
\hline
\end{tabular}
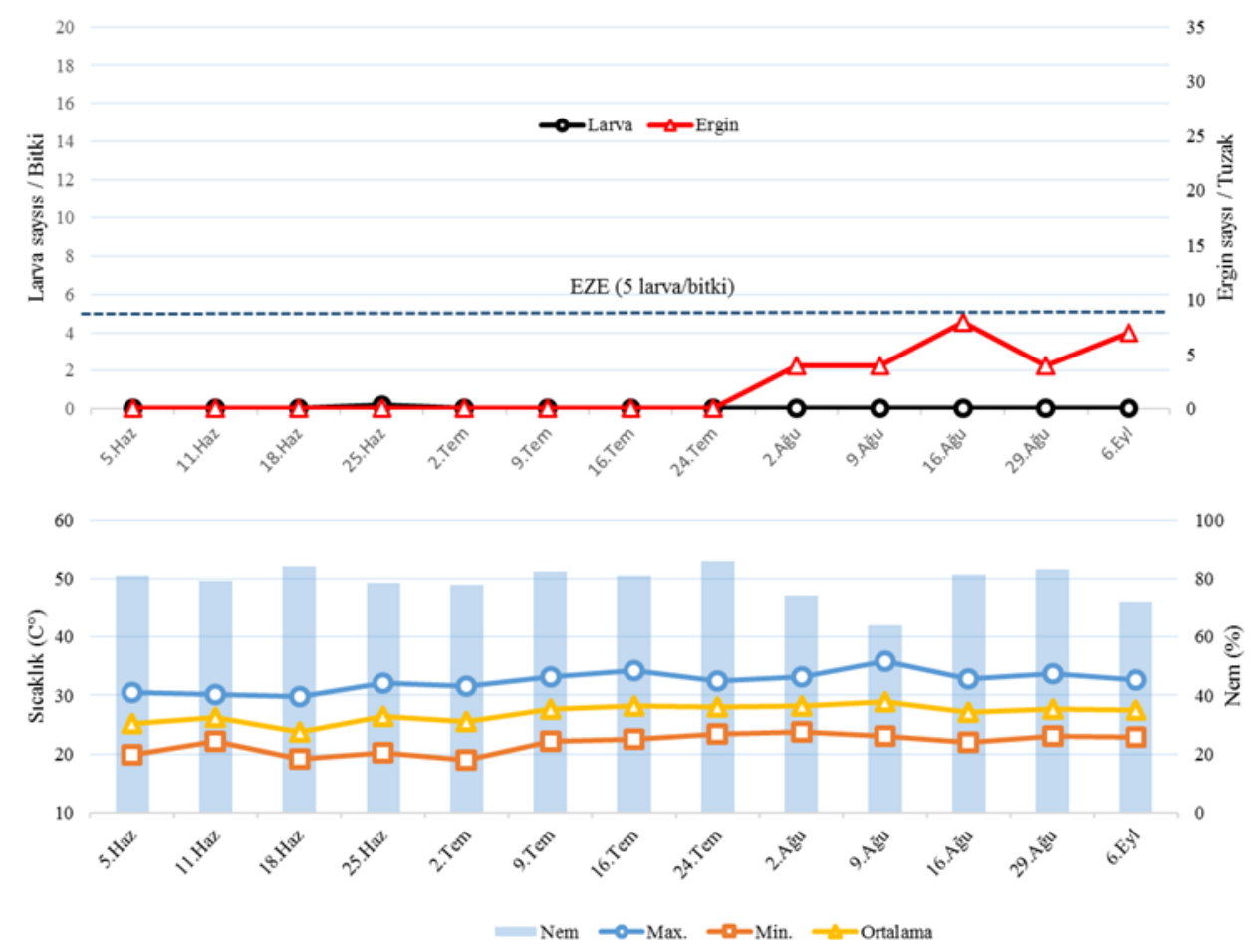

Şekil 3. Adana'da 2018 yılında yerfıstığında Helicoverpa armigera 'nın ergin ve larva popülasyonu ile meteorolojik veriler Figure 3. Meteorological data with the adult and larval population of Helicoverpa armigera in peanuts in Adana in 2018

H. armigera'nın popülasyon takibine içerisinde toplamda $716.2 \mathrm{~mm}$ yağış düştüğü, en başlanmadan önceki iklim koşullarına bakıldığında Kasım 2017 - Mayıs 2018 aylarında toplamda 69 fazla yağışın Ocak ayında 19 günde 335.9 mm günün yağışlı olduğu görülmektedir. Bu süre olarak kayıt edilmiştir (Çizelge 6). 
Çizelge 6. Adana'da 2018 yılında H. armigera'nın popülasyon takibi yapılmadan önceki dönemde toplam yağış ve yağışlı gün sayısı

Table 6. Total number of rainy and rainy days in Adana in 2018 before the population monitoring of $\mathrm{H}$. armigera

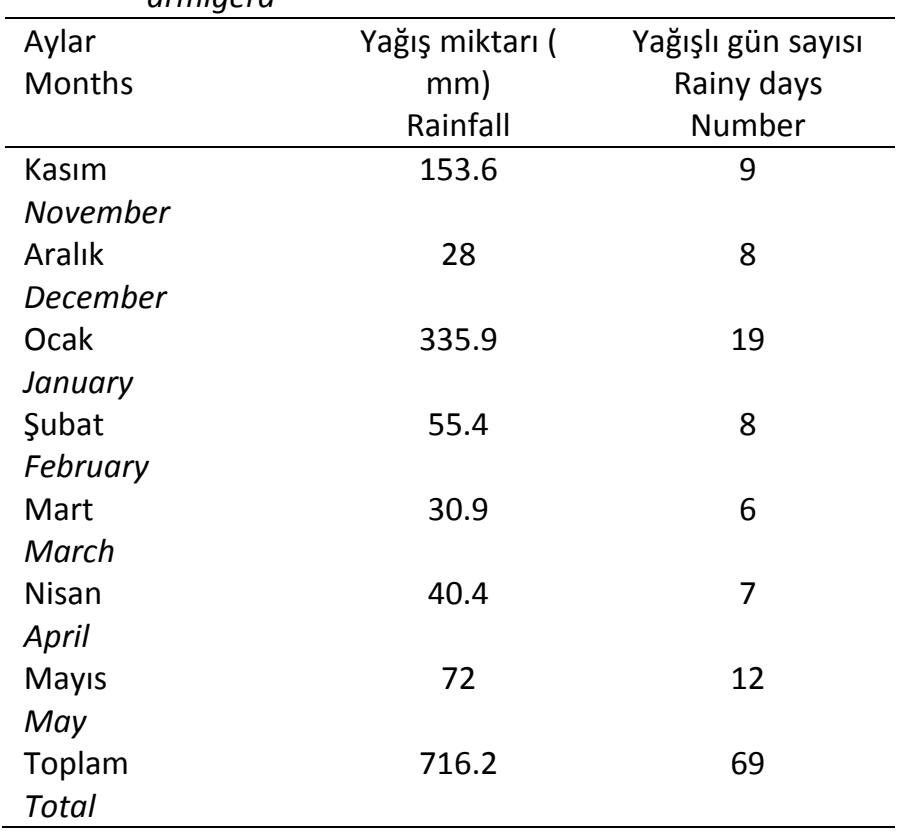


Şekil 4. Osmaniye'de 2018 yılında yerfıstığında Helicoverpa armigera'nın ergin ve larva popülasyonu ile meteorolojik veriler

Figure 4. Meteorological data with the adult and larval population of Helicoverpa armigera in peanuts in Osmaniye in 2018

H. armigera'nın popülasyon takibine başlanmadan önceki iklim koşullarına bakıldığında Kasım 2017 - Mayıs 2018 aylarında toplamda 92 günün yağışlı olduğu görülmektedir. Bu süre
Illk ergin sayımı Osmaniye'de 05.06.2018'de yapılmış ve 03.09.2018'e kadar devam edilmiştir. Illk ergin tuzağa 05.06.2018'de yakalanmıs, zararlının ergin popülasyonu ise 24.07.2018 ilk tepe noktasında 4 ergin sayılmış, 13.08.2018'de 2 ergin ile ikinci tepe noktasına ulaşmıştır Zararlının larva popülasyonunu tespit etmek için larva sayımına 05.06.2018'de başlanmıştır. illk larva tespiti 02.07 .2018 'de yapılmış, larva popülasyonu ise $16.07 .2018^{\prime} \mathrm{de} 1.2$ larva/bitki ile tepe noktasına ulaşmış ve üretim sezonu boyunca EZE altında kalmıştır. Bu nedenle bu alanda insektisit uygulaması yapılmamıştır. Popülasyon takibinin yapıldığı dönemde meteorolojik verilere bakıldığında maksimum sıcaklık 2 Temmuz'da $42.8{ }^{\circ} \mathrm{C}$ ölçülmüştür. Minimum sıcaklık ise 5 Haziran $19.3^{\circ} \mathrm{C}$ olarak ölçülmüştür. Bağıl nem ise popülasyon takibinin yapıldığı dönemin genelde \% 60'ın üzerinde seyretmiş, en yüksek bağıl nem değeri 5 Haziran'da \%74.8 olarak ölçülmüştür (Şekil 4). 
Çizelge 7. Osmaniye'de 2018 yılında H. armigera'nın popülasyon takibi yapılmadan önceki dönemde toplam yağış ve yağışlı gün sayısı

Table 7. Total number of rainy and rainy days in Osmaniye in 2018 before the population monitoring of $\mathrm{H}$. armigera

\begin{tabular}{|c|c|c|}
\hline $\begin{array}{l}\text { Aylar } \\
\text { Months }\end{array}$ & $\begin{array}{c}\text { Yağış miktarı } \\
\text { (mm) } \\
\text { Rainfall }\end{array}$ & $\begin{array}{l}\text { Yağışlı gün sayısı } \\
\text { Rainy days number }\end{array}$ \\
\hline $\begin{array}{l}\text { Kasım } \\
\text { November }\end{array}$ & 105.2 & 10 \\
\hline $\begin{array}{l}\text { Aralık } \\
\text { December }\end{array}$ & 44.6 & 12 \\
\hline $\begin{array}{l}\text { Ocak } \\
\text { January }\end{array}$ & 137.6 & 17 \\
\hline $\begin{array}{l}\text { Şubat } \\
\text { February }\end{array}$ & 54.6 & 10 \\
\hline $\begin{array}{l}\text { Mart } \\
\text { March }\end{array}$ & 54.1 & 15 \\
\hline $\begin{array}{l}\text { Nisan } \\
\text { April }\end{array}$ & 40.3 & 7 \\
\hline $\begin{array}{l}\text { Mayıs } \\
\text { May }\end{array}$ & 50.4 & 21 \\
\hline $\begin{array}{l}\text { Toplam } \\
\text { Total }\end{array}$ & 486.8 & 92 \\
\hline
\end{tabular}

Yerfıstığında zararlının popülasyon takibinin yapıldığı 2017 ve 2018 yılları birlikte incelendiğinde Temmuz ayının ilk haftasından itibaren larva popülasyonunun yükselmeye başladığı görülmektedir. H. armigera'nın larva popülasyonu 2017 yılında Adana'da 7 Temmuz-11 Ağustos arasında 0.2-1.8 larva/bitki, Osmaniye'de 28 Haziran-5 Eylül arasında 0.2-14 larva/bitki olarak değişmiştir. 2018 yılında Adana'da larva tespit edilememiş, Osmaniye'de ise 2 Temmuz- 6 Ağustos arasında 0.2-1.2 larva/bitki olarak değişmiştir. Çukurova'da pamuk alanlarında $H$. armigera larva popülasyonunun ağustos ayının sonuna doğru görülmeye başladığı bildirilmiştir (Atakan ve Boyacı 2017).

Yerfıstığında $H$. armigera'nın popülasyon takibinin yapıldığı dönemde sıcaklık ve bağıl nem ile zararlının popülasyonu arasındaki ilişkiyi belirlemek için korelasyon katsayısı hesaplanmıştır.

Çizelge 7. Adana ve Osmaniye illerinde Helicoverpa armigera'nın popülasyon değişiminin iklimsel veriler ile korelasyonu Table 7. Correlation of population change of Helicoverpa armigera with climatic data in Adana and Osmaniye provinces

\begin{tabular}{|c|c|c|c|c|c|c|}
\hline il & Dönemi & Yıl & $\begin{array}{l}\text { Maksimum } \\
\text { sıcaklık }\end{array}$ & $\begin{array}{l}\text { Minumum } \\
\text { sıcaklık }\end{array}$ & Ortalama sıcaklık & Bağıl nem \\
\hline \multirow{4}{*}{$\begin{array}{l}\frac{\pi}{2} \\
\frac{\pi}{0} \\
\frac{0}{2}\end{array}$} & Larva & & 0.071 & 0.294 & 0.361 & 0.257 \\
\hline & Ergin & 2017 & 0.313 & -0.314 & -0.088 & -0.592 \\
\hline & Larva & \multirow[b]{2}{*}{2018} & -0.065 & -0.282 & -0.107 & -0.022 \\
\hline & Ergin & & 0.410 & 0.467 & 0.391 & -0.310 \\
\hline \multirow{4}{*}{  } & Larva & & 0.405 & 0.163 & 0.305 & 0.072 \\
\hline & Ergin & 2017 & 0.159 & 0.170 & 0.076 & 0.102 \\
\hline & Larva & \multirow[b]{2}{*}{2018} & 0.180 & 0.202 & 0.234 & -0.199 \\
\hline & Ergin & & -0.193 & 0.193 & 0.014 & 0.315 \\
\hline
\end{tabular}

Bu veriler ışığında $H$. armigera'nın 2017 ve 2018 yıllarında Adana ve Osmaniye'de yerfıstığındaki popülasyon değişimi ile maksimum, minimum, ortalama sıcaklık ile bağıl nem arasındaki korelasyon katsayıları incelendiğinde anlamlı bir ilişki bulunamamıştır.

\section{Sonuç}

Bu çalışmanın yürütüldüğü yıllarda ve illerde $H$. armigera'nın yerfıstığında yaygınlık, bulaşma oranı, popülasyon değişimi tespit edilmiştir. Zararlının yerfıstığındaki popülasyon artışı birinci üründe çiçeklenme döneminden sonra görülmüştür. $H$. armigera'nın daha çok generatif organlarda verdiği zarar önemli olmasından dolayı yapraklarda meydana getirdiği zarar kısmen kabul edilebilir bulunmuştur. Bununla birlike ikinci ürün yerfıstığında ayrıca çalışma yürütülmesi önerilir.

\section{Ekler}

Bu çalışma Adana Biyolojik Mücadele Araştırma Enstitüsü tarafından desteklenen Yüksek Lisans Tezinden hazırlanmıştır. 


\section{Çıkar çatışma beyanı}

Makale yazarları aralarında herhangi bir çıkar çatışması olmadığını beyan ederler.

Yazar Katkısı: MB ve ES çalışmayı tasarlayarak verileri analiz etmiş, $M B$ ve $E S$ çalışmayı yürütmüş, $M B$ ve ES denemeleri kurmuş, $M B$ ve ES makaleyi yazmıştır.

\section{Kaynaklar}

Alkan, B., (1948). Orta Anadolu Hububat Zararlıları (Zararlı Hayvan ve Böcekler). A. Ü. Ziraat Fakültesi Yayınları, Ankara Ün. Basımevi, Ankara.

Anonim, $2012 \quad$ URL http://www.tarim.gov.tr/ TAGEM/Belgeler /yayin/ Bitki\%20Zarar I\%C4\%B1lar \%C4\%B1\%20Zirai \%20M\%C3\%BCcadele \%20Teknik \%20Talimatlar \%C4\%B1.pdf

Anonim (2018) Türkiye İstatistik Kurumu (TUiK) https://biruni.tuik.gov.tr/medas/?kn=92\&locale=tr

Anonymous, 2016. Food and Agriculture Organization of the United Nations

(FAOSTAT) http://www.fao.org/faostat/en/\#data/QC.

Arıoğlu, E. \& Arıoğlu, H., (2007). Ana ürün yerfıstığı yetiştiriciliğinde bitki yoğunluğunun verim ve bazı tarımsal özelliklere etkisi. Türkiye VII. Tarla Bitkileri Kongresi, 25-27 Haziran 2007, (2) 557-561 Erzurum, Turkey.

Arıoğlu H.H., (2014). Yağ Bitkileri Yetiştirme Ve Islahı. Çukurova Üniversitesi, Ziraat Fakültesi Ders Kitabı Genel Yayın No:220, Ders Kitapları Yayın A-70, Adana

Atakan, E., \& Boyacı M., (2017). Pamukta farklı ekim şekli ve ekim zamanının yeşilkurt (Helicoverpa armigera Hübner Lepidoptera: Noctuidae) popülasyonuna ve bitki gelişmesine etkisinin araştırılması. Türkiye Entomoloji Bülteni, 7 (2): 145-158. dol: http://dx.doi.org/10.16969/entoteb.289802

Bora, T. \& Karaca, í. (1970). Kültür Bitkilerinde Hastalığın ve Zararın Ölçülmesi. Ege Üniversitesi Zir. Fak. Yardımaı
Ders Kitabı, No: 167.

Kaya, M. \& Kovancı, B., (2000). Bursa ilinde yeşilkurt, Helicoverpa armigera (Hübner)(Lepidoptera:Noctuidae)'nın biyolojisi üzerinde araştırmalar. Yüzüncü Yıl Üniversitesi, Ziraat Fakültesi, Tarım Bilimleri Dergisi , 10(1): 37-43.

Bektaş Karapınar, Ö. \& Sertkaya, E. (2020). Diyarbakır domates alanlarında zararlı Yeşilkurt [Helicoverpa armigera (Hübner) (Lepidoptera: Noctuidae)]'un popülasyon gelişimi, parazitoit ve predatörlerinin belirlenmesi. Bitki Koruma Bülteni, 60(2): 73-82. doı: 10.16955/bitkorb.556940

Koçlu, T. \& Karsavuran, Y., (2000). Helicoverpa armigera (Hübner) (Lepidoptera: Noctuidae)'nın Manisa ilinde biyolojisi ve popülasyon düzeyi. Türkiye Entomoloji Dergisi, 24 (3) : 179-194.

Naik C.M., Chackravarthy A.K., \& Naik T.B., (2013). Population dynamics and management of Helicoverpa armigera (Hübner) (Noctuidae:Lepidotera) on groundnut in Coastal Karnataka. Enviroment\&Ecology, 31 (1): 54-57.

Öğütçü, Z., (1969), Yerfıstığı ve Ziraatı. Türkiye Ticaret Odaları, Sanayi Odaları ve Ticaret Borsaları Birliği Matbaası, Ankara.

Öngören, K., Kaya, N. \& Türkmen, Ş., (1977). Ege Bölgesi'nde domateslerde zarar yapan yeşilkurt (Heliothis armigera Hüb.)'un morfolojisi, biyolojisi ve mücadelesi üzerinde araştırmalar. Bitki Koruma Bülteni,17(1), 3-28.

Sharmila, T. \& Manjula K., (2015). Field evaluation of oil formulations of Nomuraea rileyi (Farlow) Samson against Spodoptera litura and Helicoverpa armigera in groundnut. International Journal of Plant Protection 8: 142-147. dol: 10.15740/HAS/IJPP/8.1/142-147

Uygun,N., Ulusoy, M.R., \& Başpinar, H.,, (2009) Sebze Zararlıları. Ç.Ü Ziraat Fak.Genel Yayın No: 213, Ders Kitapları Yayın No: A-68, Adana

Yabaş, M.N., (1979). Çukurova Bölgesi'nde Helicoverpa cinsine giren armigea ve zea gruplarının biyoekolojileri. Ankara Üniversitesi Ziraat Fakültesi Entomoloji Kürsüsü, Doktora Tezi (195 s). 